\author{
ЕЛЕНА ЮРЬЕВНА ИВАНОВА \\ Санкт-Петербургский государственный университет \\ Санкт-Петербург, Россия
}

\title{
Проблемы сопоставительного синтаксиса славянских языков
}

Несколько десятилетий, прошедших после выхода классической работы Романа Мразека Сравнительный синтаксис славянских литературных языков: Исходные структуры простого предложения (1990), казалось бы, должны были ознаменоваться новыми, масштабными сопоставительными исследованиями славянских языков. Однако серьезные теоретические вызовы современной науки, с одной стороны, и осознание необходимости многоаспектного (прежде всего структурно-семантического, семантического, референциального, коммуникативного) подхода к описанию синтаксических явлений, с другой, привели к пониманию того, что на данном этапе более эффективными могут быть двух-трехъязычные сопоставительные исследования наиболее важных участков грамматической системы, основанные на применении единого подхода, как, напр., серия Gramatyka konfrontatywna butgarsko-polska (1988-2009); см. также о задачах и методах изучения славянских языков в сопоставительном аспекте содержательный сборник Контрастивна проучавања српског језика: правичи и резултати (Клајн, Пипер 2010).

Многие из теоретических проблем в области сопоставительного синтаксиса, казавшихся еще до недавнего времени труднопреодолимыми, на данный момент можно считать уже почти решенными. К таковым относится, например, комплекс вопросов, связанных с описанием клитик и порядка слов. Благодаря масштабному исследованию порядка слов в славянских языках Антона Владимировича Циммерлинга (2013) получена надежная теоретическая база и понятный инструментарий для изучения закономерностей организации клитик в цепочки и основных линейно-акцентных преобразований в предложении.

Достигнуты в целом единообразные результаты при описании референциальных аспектов славянского предложения благодаря применению рефе- 
ренциально-прагматического подхода, независимо от прилагаемых вариантов теории референции (Гаргов, Косеска-Тошева 1990; Иванова 2015а и др.).

Далее остановлюсь на двух важнейших задачах, встающих перед исследователем при описании системы синтаксиса двух и более славянских языков: 1) необходимость обязательного учета достижений семантической лингвистики и 2) установление параллелей между балкано-славянской $\partial a$-конструкцией и ее аналогами в других славянских языках.

\section{1. Семантический аспект синтаксиса и его применение в сопоставительных исследованиях славянских языков}

Разные виды семантического структурирования языковой системы, которые предлагаются современной наукой, могут быть эффективно использованы при сопоставительном изучении синтаксиса двух или более языков. Семантические исследования предшествующих десятилетий продемонстрировали, что при любой классификации предложений основное внимание должно уделяться предикату как структурному и смысловому организующему центру, при этом основанием классификации может являться либо семантика признака, заключенного в предикате (Мразек 1990), либо вся предикатно-актантная структура, что позволяет связать семантику предложения с количеством и характером обязательных компонентов пропозиции (Адамец 1978). Даже пропозиционально-семантические (Шмелева 1994; Гладров 2002) и логико-семантические (Арутюнова 1976) классификации, которые учитывают прежде всего характер мыслительного процесса, организующего пропозицию, на последующих ступенях классификации неизбежно обращаются к семантике предиката.

Очевидна значимость появления «классификационных сеток» (Булыгина 1982; Селиверстова 1982 и др.), представляющих варианты таксономии предикатов. Семантические типы предикатов (которые мыслятся и как классы ситуаций) устанавливают наиболее типичные соотношения между семантикой предиката и характером отображаемой ситуации. Они выявляются при учете таких основных факторов, как локализованность или не локализованность признака во времени, его статичность или динамичность, контролируемость или неконтролируемость. Основы семантической типологии предикатов были заложены еще в классической статье Ю.С. Маслова (1948) о связи вида глагола с его лексическим значением и - независимо от этой публикации - исследованиями Зено Вендлера (Vendler 1957). Многие положения семантической типологии, выдвинутые в данных работах, впоследствии были существенно дополнены и переработаны западными и славянскими лингвистами (Miller 1970; 
Ljung 1975; Dic 1978; Булыгина 1982; Селиверстова 1982; Падучева 1996, 2004 и др.). В лингвистический оборот был введен признак «контролируемость действия», позволивший создать интересную и надежную систему координат, полезную не только для аспектологии, но и для синтаксической типологии. Оказалось, что «большинство сочетаемостных характеристик глагола привязано именно к семантическим признакам» (Падучева 1996: 128), поэтому предикаты разных типов проявляют общегрупповые особенности синтаксического и - шире - грамматического поведения, что и позволяет осмыслять классы предикатов как классы ситуаций.

Заметим, что семантическая типология предикатов находит свое применение в сопоставительных исследованиях славянских языков, как правило, лишь как важнейший инструмент лингвистического анализа, но не в чистом виде, как определяющий принцип классификации синтаксических структур. Принято считать, что использование семантической таксономии предикатов в сопоставительном аспекте может дать интересные результаты лишь при отсутствии близкого родства языков, при значительном отличии видо-временных систем, что позволяет, например, показать роль видового противопоставления в славянских языках на фоне языков, не обладающих категорией вида. Действительно, стоит ли проводить сопоставление (близко)родственных языков, если общий семантический тип предиката, отражая онтологически схожие ситуации, задает и одинаковые синтаксические характеристики? Тем не менее даже класс «устойчивых признаков», ожидаемо близкий в разных славянских языках, предлагает значимый набор грамматических и деривационных расхождений (Иванова 2012). Еще более эффективным представляется изучение «актуальных» предикаций, как статических (класс «состояний»), так и динамических - классы «процессов» и «событий». В синтаксическом томе Conoставительной болгарско-русской грамматики (Иванова 2009) семантическая типология предикатов описывается в рамках другой важнейшей для славистики семантической классификации - логико-семантической типологии предложений ${ }^{1}$. Наложение двух классификаций создает своеобразную сетку, в ячейках которой предлагаются наборы логико-синтаксических структур, реализующие те или иные логико-семантические отношения.

Семантический подход в качестве концептуальной основы сопоставления выбран и в обеих наиболее значительных на данный момент сериях (коллективных многотомных сборниках) двуязычных исследований славянских языков - Gramatyka konfrontatywna butgarsko-polska и Полски-македонски: Граматичка конфронтација.

В серии Gramatyka konfrontatywna butgarsko-polska (1988-2009), являющейся самым масштабным двуязычным сопоставительным проектом, языковые

1 Логико-семантический подход к изучению построений естественного языка был реализован на русском материале Ниной Давидовной Арутюновой (1976). 
семантические категории сопоставляются посредством логико-семантического языка-посредника, что позволяет вписать данные обоих языков в стройную систему координат и создать объемную картину морфосинтаксических и синтаксических явлений польского и болгарского языков.

Подход, применяемый для сопоставительного описания македонского и польского языков в рамках серии Полски-македонски: Граматичка конфронтација (1999-2015), исследует механизмы деривации - механизмы, которые позволяют выявлять, «како во јазикот Б се изразува информацијата, која во јазикот А се пренесува со граматички средства, и обратно» (Тополињска 2003: 7), и такое сопоставление производится на основе деривационного подхода. Отличительной особенностью этой серии является учет явлений словообразовательного уровня и применение механизмов деривации при анализе крупных участков синтаксической системы, что позволяет выявить интересные параллели между словообразованием и морфосинтаксисом. Обращение же к диахроническим сведениям дает возможность проследить пути и способы грамматикализации семантических признаков.

Обе упомянутые сопоставительные серии подтверждают тот факт, что современная синтаксическая наука является, несомненно, семантически ориентированной.

\section{2. Да-конструкция и сослагательное наклонение как средства выражения нефактивности}

\section{1. Балкано-славянская да-конструкция}

Важнейшие синтаксические различия между славянскими языками связаны с фактором отсутствия/наличия в грамматической системе языка т.н. $\partial a$-конструкции. Принципиальное различие синтаксиса языков с заменой инфинитива да-конструкцией и языков с сохраненным (в той или иной мере) инфинитивом просматривается на многих значимых участках синтаксической системы, в основном соотносимых с семантическими зонами ирреальности/нефактивности. В балкано-славянских языках наблюдается расширение функций да-форм, ведущее, с одной стороны, к усложнению семантического потенциала да-конструкции и, с другой, к нарушению прочной связи да и последующего глагола, что выражается в ослаблении синтаксических и морфологических ограничений при употреблении данной конструкции и возникновению новых частиц и моделей, сохраняющих, тем не менее, значение нефактивности, присущее да-формам, см., например, работы, показывающие формирование новых эпистемических частиц - макед. да не и болг. да не би (Бужаровска, Митковска 2015; Иванова 2014). 
В сборнике Субјунктив со посебен осврт на македонските да-конструкции (2015), подготовленном Македонской АН, содержится много важнейших статей двуязычного сопоставительного характера, которые иллюстрируют широкий спектр языковых явлений, связанных с функционированием $\partial a$-конструкции в балкано-славянских языках. Для сопоставления этих структур с их аналогами в языках без $\partial a$-конструкции требуется масштабный межъязыковой анализ. Так, основные только неграмматикализованные употребления $\partial a$-конструкции в южнославянских языках, связанные с зоной ирреальности / нефактивности, найдут, например, в русском языке соответствие в разных участках языковой системы, которые находятся между собой в очевидном или неочевидном соприкосновении: зоны императивности/ оптативности, сослагательности, интеррогативности, модальности, аппроксимативности (Субјунктив 2015: 100-153 и др.).

Значительные зоны соприкосновения имеются между $\partial a$-конструкцией и условным (сослагательным) наклонением. Оба явления представляют зону нефактивных предикаций. Семантическую близость балкано-славянской $\partial a$-конструкции и форм условного (сослагательного) наклонения в небалканских славянских языках подтверждают двуязычные параллели в разных типах сложноподчиненных предложений (Субјунктив 2015; Градинарова 2010; Иванова 2015б). В качестве примера далее сопоставим условия формирования гипотетических относительных придаточных в болгарском и русском языках.

Прежде чем продемонстрировать эти параллели, заметим, что использование связующих средств с $\partial a$ резко ограничивает временную амплитуду сказуемого придаточного предложения - настоящее время при настоящих и будущих гипотетических ситуациях, перфект (реже плюсквамперфект) для ситуаций прошлого 2 , ср.: Няма човек, който да ме спаси (PRES). - Нет человека, который мог бы меня спасти; Няма човек, който да не е чувал (PERF) за него. - Нет человека, который бы не слышал о нем. Ранее в болгарском языке было допустимо сослагательное наклонение в таких придаточных: Едва ли имаше човек в Мечи дол, който да би излязъл (COND) наглава с него (А.Тодоров) (Захаревич, Крылова 1978: 37), но сейчас болгарский кондиционал резко сузил зону своего применения, уступив во всех типах придаточных предложений изьявительному наклонению.

\section{2. Относительные придаточные с гипотетическим значением}

В болгарских относительных придаточных с гипотетическим значением союзные относительные слова който, какъвто, чийто, когато, където могут иметь модальное наращение $\partial a$. Оно регулярно появляется в тех же кон-

2 Такое же ограничение наблюдается и во многих других зависимых клаузах, где содержится $\partial a$ в качестве основного средства связи или в составе такого средства. 
текстах, которые предполагают использование сослагательного наклонения в русских относительных придаточных.

Схожесть условий, в которых присутствует наращение $\partial a$ в болгарском языке и сослагательное наклонение в русском, обусловлено спецификой гипотетического относительного придаточного - оно определяет несуществующие объекты или такие, о существовании которых ничего не известно (Добрушина 2011).

2.2.1. В большинстве случаев в главном предложении содержится сообщение о несуществовании характеризуемого объекта; обычно имеется эксплицитное предикатное отрицание: И в нито един от тях [домовете] не намираха някаква вещ, която да докаже, че пеперудите водят разумно съществуване (П. Вежинов). — И ни в одном из них [домов] не заметили они ни одной вещи, которая бы свидетельствовала, что бабочки ведут образ жизни разумных существ (пер. Р. Белло); Няма жена на тоя свят, която поне веднъж през живота си да не направи нещзо безумно и непоправимо (П. Вежинов). - Нет женщины, которая хоть раз в жизни не совершила бы чего-то безрассудного и непоправимого (пер. М. Тарасовой). Отрицание может быть и имплицитным: Липсвала здрава ръка, която да стегне всичко (Д. Димов). - букв. Отсутствовала крепкая рука, которая бы все держала.

2.2.2. Несуществование характеризуемого объекта может быть задано придаточным потенциального условия (далее подчеркнуто): И всред това щуастие той съзна изведнъж, че ако имаше и един кон, с който да прекарва дърва в града, не би желал нищо повече (Д. Димов). - И посреди этого счастья он вдруг осознал, что, если б у него была лошадь, на которой он мог $б ы$ перевозить дрова в город, ему бы более ничего не нужно было.

2.2.3. Сомнение в существовании объекта может быть имплицировано в риторическом вопросе: Има ли човек, който да го надприказва? - Есть ли человек, который бы его переговорил?

2.2.4. На необходимость появления нового объекта указывают модальные глаголы: Трябва ни човек, който да вкарва по 15-20 гола на сезона. Нам нужен человек, который бы забивал по 15-20 голов в сезон. Снятие пресуппозиции существования объекта осуществляется и модальными расширениями при основном предикате: Сега трябва непременно да ѝ кажеш нещзо, което да я успокои. - Сейчас ты должен непременно сказать ей что-нибудь, что́ бы ее успокоило.

2.2.5. Некоторые наречия и наречные выражения способны указывать на малую вероятность существования объекта: Рядко се срещат хора, които да не притварят блажено очи, когато усетят нежния аромат на ванилия (Интернет). - Редко встречаются люди, которые бы не прикрывали блаженно глаза, когда почувствуют нежный аромат ванили.

2.2.6. Вне указанных выше контекстов (отрицания, сомнения, модальности), по наблюдениям Н.Р. Добрушиной над данными русского языка, 
возможно введение гипотетического придаточного при предикатах с семантикой создания нового объекта (организовать, подготовить, разработать, сочинить), введения нового объекта в личную сферу (искать, ждать, назначить, пригласить, представить себе): Я всю жизнь ждал человека, который мог бы понять меня (Ю. Азаров); Потом в троллейбусе я живо представил себе обстоятельства, при которых мог бы познакомиться с ней... (К. Шахназаров). В болгарском языке в соответствующих контекстах будет выбрано да-наращение: Все щете да се намери някой, който да ви отвори очите (С. Стратиев); ...аз просто усещам как напряга бедната си глава с надежда да измисли в последния миг нещо, което да иे послужи за юзда, но не може да измисли нищо (Б. Райнов); Искам да кажа, отеи Сандовал позволява да работим заедно само ако се съгласите да съединим двете болници в една, която да функиионира от името на ордена (Д. Димов).

\section{3. Относительные придаточные с контрфактивным значением}

Иная ситуация в русско-болгарских соответствиях наблюдается в случае относительного придаточного, которое содержит информацию о положении дел, которое не может быть осуществлено. В русском языке сослагательное наклонение используется лишь в тех контрфактивных придаточных, которые содержат указание на какие-л. альтернативные условия, при которых ситуация была бы осуществлена в альтернативном мире (в альтернативном месте, времени, альтернативным лицом): Объяснить эту ненормальную ситуацию, которая в любой другой стране была бы, наоборот, нормой, не берусь (Э. Рязанов); Но Самоделкин умеет мастерить такие сложные машины, которые я ни за что не смог бы нарисовать (В. Постников), см. подробнее указанную статью Н.Р. Добрушиной.

В болгарском языке при относительных придаточных с контрфактивным значением употребляется не $\partial a$-наращение, а условное наклонение: Ехал он и размышлял о той пользе, какую приносили бы (COND) театры, если бы в них давались пьесы нравственного содержания (А.П. Чехов). - Той седеше в екипажа и мислеше за ползата, която би имало (COND) от театрите, ако в тях се даваха пиеси с нравствено съдържание (пер. К. Койчевой). Таким образом, для $\partial a$-конструкции в относительных придаточных значение контрфактичности не характерно.

Как показывает изучение и других сложноподчиненных предложений, балканославянский модальный элемент $\partial а$ функционирует прежде всего в зоне ирреальности, связанной с возможными или предполагаемыми ситуациями (Генадиева-Мутафчиева 1970; Тополиньска 2008, Субјунктив 2015; Иванова 20156 и др.). 


\section{3. Заключение}

За последние десятилетия синтаксическая славистика обогатилась серией работ, представивших эффективную методику исследования близкородственных языков и позволивших решить ряд важных теоретических вопросов сопоставительного синтаксиса. Высокую результативность показывает применение семантического подхода или, по крайней мере, учет результатов семантических исследований для описания синтаксических явлений.

Одной из важнейших задач сопоставительного синтаксиса является исследование комплекса средств, относящихся к зоне ирреальности / нефактивности. Этот анализ должен учитывать разное распределение способов выражения нефактивности в языках с представленностью $\partial a$-конструкции и без нее. Для более отчетливого видения сферы действия $\partial a$-конструкции и ее соответствий в небалканских славянских языках необходимо описание значительных фрагментов синтаксической системы, в которых были бы сопоставлены средства выражения нефактивных ситуаций ${ }^{3}$.

\section{Библиография}

Адамец П., 1978, Образование предложений из пропозиций в современном русском языке. Praha. Арутюнова Н.Д., 1976, Предложение и его смысл: Логико-семантические проблемы. Москва. Бужаровска Е., Митковска Л., 2015, Негираните независни да-конструкиии, [в:] Субјунктив со посебен осврт на македонските да-конструкции, ред. 3. Тополињска. Скопје, с. 23-46.

Булыгина Т.В., 1982, К построению типологии предикатов в русском языке, [в:] Семантические типы предикатов. Москва, с. 7-85.

Гаргов Г., Косеска-Тошева В., 1990, Българско-полска съпоставителна граматика. Т. 2. Семантичната категория определеност / неопределеност. София.

Генадиева-Мутафчиева 3., 1970, Подчинителният съюз ДА в съвременния български език. София.

Гладров В.В., 2002, В.В. Виноградов и формирование современной концепщии синтаксиса русского языка, «Вестник Московского университета. Сер. 9: Филология», 1, с. 22-33.

Градинарова А.А., 2010, Фрагменты болгарско-русского сопоставительного синтаксиса: Учебное пособие. София.

Добрушина Н.Р., 2011, Сослагательное наклонение в относительных придаточных с союзом который, «Вестник МГУ. Сер. 9: Филология», 6, с. 69-83.

Захаревич Е.А., Крылова Г.В., 1968, Болгарский язык: Методические указания, теоретический комментарий, тексты и упражнения по синтаксису простого предложения. Ленинград.

Иванова Е.Ю., 2012, Славянские языки в аспекте типологии предикатов (класс «устойчивых признаков»), «Филология и человек» 3, с. 72-86.

Иванова Е.Ю., 2009, Сопоставительная болгарско-русская грамматика. Синтаксис: T. 2. София.

${ }^{3}$ Исследование проводится при поддержке Российского гуманитарного научного фонда (проект № 16-04-50019) и в рамках Основного трудового договора с СПбГУ. 
Иванова Е.Ю., 2014, Апрехенсивное значение в русском и болгарском языках, «Studi Slavistici», XI, c. $143-168$.

Иванова Е.Ю., 2015а, Артиклевая система болгарского языка в работах Ю.С. Маслова и в современных концепииях, «Вестник СПбГУ. Серия 9: Филология. Востоковедение. Журналистика», 3, с. 84-97.

Иванова Е.Ю., 2015б, Българската да-конструкиия и руското съслагателно наклонение: зони на пресичане и разминаване, [в:] Проблемы когнитивного и функиионального описания русского и болгарского языков. Выпуск IX. Шумен: Ун-ско изд-во «Епископ Константин Преславски», с. 5-28.

Контрастивна проучавања српског језика: правци и резултати, 2010, ред. И. Клајн, П. Пипер. Београд: САНУ.

Маслов Ю.С., 1948, Вид и лексическое значение глагола в современном русском литературном языке, «Изв. АН СССР. Сер. лит. и яз.», т. 7, № 4, с. 303-316.

Мразек Р., 1990, Сравнительный синтаксис славянских литературных языков: Исходные структуры простого предложения. Вrno.

Падучева Е.В., 1996, Семантические исследования: Семантика времени и вида в русском языке. Семантика нарратива. Москва.

Полски-македонски: Граматичка конфронтачија, 1999-2015, Тополињска 3. (уред.), т. 1-10. Скопје.

Селиверстова О.Н., 1982, Второй вариант классификационной сетки и описание некоторых предикатных типов русского языка, [в:] Семантические типы предикатов. Москва, s. $86-157$.

Субјунктив со посебен осврт на македонските да-конструкции. 2015. Тополињска 3. (уред.), Скопје.

Тополињска 3., 2003, Полски-македонски: Граматичка конфронтација, m. 6: Синтаксичка дериваиија. Скопје.

Тополињска 3., 2008, Полски-Македонски: Граматичка конфронтаџија, m. 8: Развиток на граматичките категории. Скопје.

Циммерлинг А.В., 2013, Системы порядка слов славянских языков в типологическом аспекте. Москва.

Шмелева Т.В., 1994, Семантический синтаксис: Текст лекций из курса «Современный русский язык». 2-е изд. Красноярск.

Янко Т.Е., 2008, Интонационные стратегии русской речи в сопоставительном аспекте. Москва.

Dik S.C., 1978, Functional Grammar. Amsterdam.

Gramatyka konfrontatywna butgarsko-polska, 1988-2009, т. 1-9, red. serii S. Ivančev, V. Koseska-Toszewa, J. Penčev (т. 1-2); V. Koseska-Toszewa, J. Penčev (т. 3-9), Sofia-Warszawa.

Ljung M., 1975, State control, «Lingua», v. 37, n 2/3, c. 129-150.

Miller J.E., 1970, Stative verbs in Russian, «Foundations of language», v. 6, c. 488-504.

Vendler Z., 1957, Verbs and times, «The philosophical review», v. 66, c. 143-160.

\section{Some issues in contrastive syntax of Slavic languages}

Summary

The paper dwells on some issues related to the work on contrastive survey of syntax in the Slavic languages. Firstly, it emphasises the importance of the properly chosen semantic basis for a contrastive analysis, taking into account the noticeable syntactic bias of modern syntactic studies. 
Secondly, the paper analyses the importance of syntactic differences between Slavic languages arising from the presence/absence of the so called $d a$ construction in the grammatical system of a language. This difference is perceptible in a number of essential segments of the syntactic system, mainly those associated with the semantic areas of irreality/non-factuality. In the area of hypotheticality, an obvious affinity is apparent between $d a$ constructions and conditional forms. Through the example of hypothetical relative clauses in Bulgarian and Russian it is shown that the said forms in these two languages occur under similar conditions.

Keywords: contrastive syntax, semantic syntax, $d a$ construction, non-factuality, Slavic languages

\section{Проблеми на съпоставителния синтаксис}

\section{на славянските езици}

Резюме

В статията се разглеждат редица проблеми на сьпоставителния синтаксис на славянските езици. Подчертава се - първо - значимостта на избора на семантичната база за съпоставителен анализ, защото съвременната синтактична наука се отличава с по-особено внимание към семантиката.

Второ, дълбочината на синтактичните разлики между славянските езици е в голяма степен свързана с това, дали в граматичната структура на езика е представена тъй наречената $\partial a$-конструкция. Разликата между езиците по този параметр се открива в различни фрагменти на синтактичната система, предимно свързани със зоните на иреалност/нефактивност. В зоната на хипотетичността има доста прилики между $\partial a$-конструкцията и кондиционала, например съпоставка между българските $\partial a$-конструкции и руския кондиционал в хипотетичните определителни изречения показва близките условия за реализация на дадени форми.

Ключови думи: съпоставителен синтаксис, семантичен синтаксис, $\partial а$-конструкция, нефактивност, славянски езици 